\title{
Correction to: Living Systems Theory: \\ Using a Person-in-Context Behaviour \\ Episode Unit of Analysis in Career \\ Guidance Research \\ and Practice
}

Fred W. Vondracek, Erik J. Porfeli, and Donald H. Ford

\section{Correction to:}

Chapter 23 in: J. A. Athanasou, H. N. Perera (eds.),

International Handbook of Career Guidance, https://doi.org/10.1007/978-3-030-25153-6_23

The original version of the book was inadvertently published with incorrect chapter title in Chapter 23 as "International Handbook of Career Guidance".

The corrected chapter title is as follows.

"Living Systems Theory: Using a Person-in-Context Behaviour Episode Unit of Analysis in Career Guidance Research and Practice"

This has now been corrected in the table of contents and in the chapter opening page. 